\title{
Influences of Two Land-Surface Schemes on RegCM4 Precipitation Simulations over the Tibetan Plateau
}

\author{
Xuejia Wang, ${ }^{1,2}$ Meixue Yang, ${ }^{1}$ and Guojin Pang ${ }^{3}$ \\ ${ }^{1}$ State Key Laboratory of Cryospheric Sciences, Cold and Arid Regions Environmental and Engineering Research Institute, \\ Chinese Academy of Sciences, Lanzhou, Gansu 730000, China \\ ${ }^{2}$ University of Chinese Academy of Sciences, Beijing 100049, China \\ ${ }^{3}$ Laboratory of Remote Sensing and Geospatial Science, Cold and Arid Regions Environmental and Engineering Research Institute, \\ Chinese Academy of Sciences, Lanzhou, Gansu 730000, China
}

Correspondence should be addressed to Meixue Yang; mxyang@lzb.ac.cn

Received 28 June 2014; Revised 2 September 2014; Accepted 2 September 2014

Academic Editor: Eduardo García-Ortega

Copyright (c) 2015 Xuejia Wang et al. This is an open access article distributed under the Creative Commons Attribution License, which permits unrestricted use, distribution, and reproduction in any medium, provided the original work is properly cited.

\begin{abstract}
The effects of different RegCM4 land-surface schemes on Tibetan Plateau (TP) precipitation simulations were investigated. Two groups of ten-year (1992-2001) simulation experiments (hereafter referred to as BATS and CLM) were performed based on two land-surface schemes (BATS and CLM3.5, resp.) and were compared with observed data using the same domain, initial, and lateral boundary conditions, cumulus convective scheme, and spatial resolution. The results showed that the CLM monthly precipitation more closely matched the observed data compared with BATS. BATS and CLM both overestimated summer precipitation in the northern TP but underestimated summer precipitation in the southern TP. However, CLM, because of its detailed land-surface process descriptions, reduced the overestimated precipitation areas and magnitudes of BATS. Compared to CN05, the regional average summer precipitation in BATS and CLM was overestimated by $34.7 \%$ and underestimated by $24.7 \%$, respectively. Higher soil moisture, evapotranspiration, and heating effects in the BATS experiment triggered changes in atmospheric circulation patterns over the TP. Moreover, BATS simulated the lower atmosphere as warmer and more humid and the upper atmosphere $(\sim 150 \mathrm{hPa})$ as colder than the CLM simulations; these characteristics likely increased the instability for moist convection and produced more summer precipitation.
\end{abstract}

\section{Introduction}

The Tibetan Plateau (TP) has a profound influence on China and global weather and climate through both dynamical and thermal effects (e.g., $[1,2]$ ), which generate the most prominent monsoon circulations on Earth. The TP is usually called the "water tower of Asia" because of its importance in the hydrological cycle. Many Asian rivers originate from the TP, including the largest rivers in the world, that is, the Indus, the Ganga-Brahmaputra, the Yellow River, and the Yangtze [3]. Precipitation is one of the most important climatic elements; it not only affects people's daily lives but also relates to climate change. Global warming and variations in precipitation characteristics have been urgent issues in climatological and hydrological studies. However, precipitation is still the most difficult climatic element to reasonably forecast because it occurs as a result of nonlinear interactions between complicated physical and dynamic processes $[4,5]$.

However, owing to the limited observational data and unevenly distributed meteorological stations on the TP, using meteorological data to study the climate on the TP, especially precipitation changes, is difficult. Therefore, high-resolution regional climate models, which can describe climate variations due to mesoscale and smaller topography, underlying surface characteristics, and other factors, have become a valuable tool for understanding climate characteristics and change and for elucidating the mechanisms involved (e.g., [6-11]). Regional climate models, which have high accuracy and low uncertainty, are able to provide adequate simulations and forecasts of climate change. To reduce the uncertainties of model simulations, we need to understand the influences of physical mechanisms and processes on climate change. 
Meanwhile, we must fully explore model sensitivities to different physical parameterization schemes and seek an appropriate parameterization scheme suitable for a particular area [8].

Recent studies suggested that cumulus convective precipitation schemes significantly affect the simulation of precipitation (e.g., $[5,12-16])$. Specifically, the configurations and focuses of local convective precipitation processes differ among the convective schemes. Moreover, the spatial resolution, topography, land use, and atmospheric boundary conditions of the schemes can discernibly influence the simulation of precipitation [4, 17-20]. Land-surface processes physically influence climate change. The underlying land conditions greatly affect the land surface energy and water balances and thereby have a far-reaching effect on local, regional, and even global atmospheric circulations and climate change. The "water gap" prevents climate simulation capabilities in current climate models. This is precisely caused by the lack of adequate awareness of the hydrological cycle. The imperfect treatment of precipitation, evaporation, and land-based hydrological processes in GCMs and inadequate parameterization schemes for land-surface process affect the simulation ability of modern GCMs and RCMs [21]. Sensitivity tests of the influences of different land-surface schemes on climate simulations have been conducted in areas outside of the TP and have not thoroughly analyzed precipitation simulations (e.g., [10, 21-24]). Therefore, a reasonable and detailed land-surface process scheme is increasingly crucial and necessary for climate simulations in the TP.

In this study, to investigate the effects of land-surface schemes in regional climate models (RegCM4) on TP climate simulations, two groups of ten-year (1992-2001) simulation experiments were performed based on two available landsurface schemes (BATS and CLM3.5). These experiments were compared with observed data by using the same domain, initial and lateral atmospheric boundary data conditions, and cumulus convective precipitation scheme, as well as a $30 \mathrm{~km}$ spatial resolution. The objective of this study is to determine an appropriate land-surface scheme for the TP and to provide a basis for precipitation simulations in this region.

\section{Model and Simulation Experiments}

Regional Climate Model version 4 (RegCM4) is the developed and improved version of the RegCM3 of the Abdus Salam International Center for Theoretical Physics. RegCM4 is a three-dimensional atmospheric model that uses a hydrostatic assumption, the Arakawa B horizontal grid system, and terrain-following sigma coordinates. It includes turbulence mixing, grid-scale and subgrid-scale cloud processes, radiative transfer processes, and land-surface processes. Compared to previous versions, many physical processes of the RegCM4 have been continuously updated. For example, it includes new land-surface, planetary boundary layer, and air-sea flux schemes, a mixed convection and tropical band configuration, and modifications to the preexisting radiative transfer and boundary layer schemes [8]. Overall, RegCM4 shows an improved performance in several respects compared to previous versions. The greatest change is that a new and more advanced Community Land Model version 3.5 (CLM3.5) was coupled to the RegCM4. A BiosphereAtmosphere Transfer Scheme (BATS) was also added as an alternative land surface scheme.

A brief comparison of the parameters and attributes of the BATS and CLM3.5 land surface schemes is given in Table 1. BATS has been described in detail by Dickinson et al. [25]. The scheme, which has been used for many years, includes a vegetation layer, a snow layer, a force-restore model for soil temperatures, and a 3-layer soil scheme. The land cover descriptions from the GLCC database consist of 20 surface types, 12 soil colors, and various soil textures, according to the FAO Soil Map of the World [26]. A mosaic-type parameterization of the subgrid-scale topography and land use was implemented. The parameterization used a regular finescale surface subgrid for each coarse-model grid cell. This scheme showed a remarkable improvement of the surface hydrological cycle simulation in mountainous regions [18].

Compared to BATS, CLM3.5 is a more advanced package, as described in detail by Oleson et al. [27, 28]. CLM3 uses a succession of biogeophysical parameterizations to describe the exchanges of energy, momentum, water, and carbon between land and the atmosphere. CLM3 divides the grid cells into a first subgrid hierarchy composed of multiple land units (glaciers, wetlands, vegetation, lakes, and urban) and second and third subgrid hierarchies for vegetated land units, including different snow/soil columns and plant functional types [27]. The percentage of sand and clay varied with depth based on the 5-minute resolution IGBP soil dataset to develop a soil texture dataset [29]. Biogeophysical processes are calculated for each land unit, column, and PFT and then averaged before returning to the atmospheric model. Soil temperature and water content are calculated with a multiple layer model. The soil column is discretized into ten layers, where the minimum and maximum depths of the soil layer are $1.75 \mathrm{~cm}$ and $3.43 \mathrm{~m}$, respectively. The overlying snow pack is modeled with up to five layers, depending on the total snow depth. CLM3.5 was updated from CLM3 by integrating Moderate Resolution Imaging Spectroradiometer (MODIS) products [30], improving the canopy integration and interception schemes [30, 31], adding a simple TOPMODEL-based model for surface and subsurface runoff [32], adding a new frozen soil scheme [33], and adding a simple groundwater model for determining the water table depth [34].

For RegCM4, we compiled the model with the two available land-surface schemes (BATS and CLM3.5). Six hourly fields from ECMWF/ERA40 reanalysis data were selected as the initial and lateral atmospheric boundary conditions for the regional model in both two experiments. Figure 1 shows the RegCM4 simulation domain and topography centered on $90^{\circ} \mathrm{E}$ and $30^{\circ} \mathrm{N}$, with $160 \times 108$ grid mesh that covers the TP and its surrounding areas. The horizontal resolution is $30 \mathrm{~km}$, and the vertical grids are composed of 23 sigma levels stretching from near the surface to the model top $(10 \mathrm{hPa})$. Sea-surface temperatures (SSTs) were acquired from NOAA optimal interpolation weekly SST data $\left(1^{\circ} \times 1^{\circ}\right.$ resolution). To maintain the model's computational stability, an integration time step of 60 seconds was used. The Grell cumulus cloud convective parameterization scheme was used 
TABLE 1: Comparisons of the BATS and CLM3.5 land-surface schemes in RegCM4.

\begin{tabular}{lcc}
\hline & BATS & CLM3.5 \\
\hline Number of soil layers & 3 & 10 \\
Soil temperature calculation & Force-restore method & Heat diffusion equation \\
Soil freezing and thawing & Yes & 5 landunits, 17 types (PFTs) represent vegetation \\
Number of snow layers & 1 & MODIS products \\
Land use parameters & 20 (GLCC) \\
Surface datasets & Leaf area index & IGBP soil dataset \\
Soil texture & FAO Soil Map of the World & 5 \\
\hline
\end{tabular}

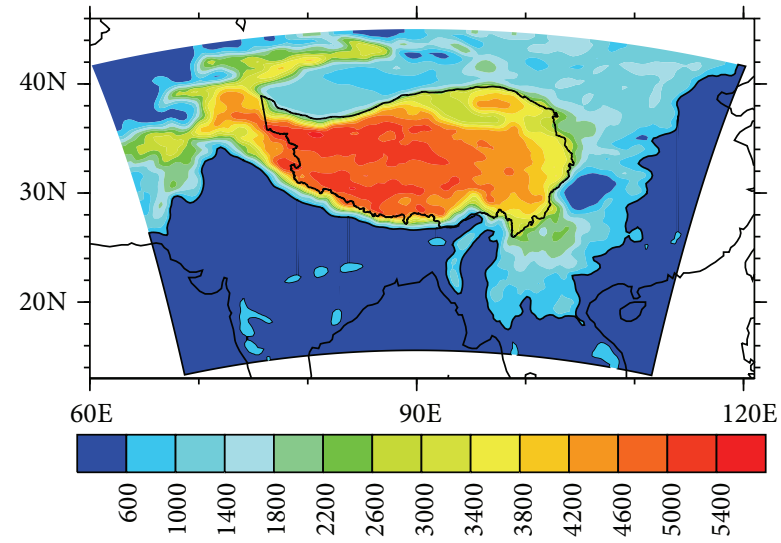

FIGURE 1: Model domain and analysis region of this experiment (unit: $\mathrm{m}$ ).

TABLE 2: Model configuration used in this study.

\begin{tabular}{ll}
\hline Contents & Description \\
\hline Horizontal grid & $160 \times 108(\Delta X=30 \mathrm{~km})$ \\
Initial and boundary & ERA40, Relaxation \\
conditions & (exponential) \\
Vertical layers (top) & 23 layers $(10 \mathrm{hPa})$ \\
Cumulus convection & Grell with Fritsch-Chappell \\
Turbulence & Holtslag scheme \\
Shortwave/longwave radiation & NCAR CCM3 \\
Analysis period & 1992-2001 \\
\hline
\end{tabular}

with the FC80 closure assumption [35] because it is better than Anther-Kuo when simulating the spatial pattern of climate over the TP [14]. The Holtslag turbulence scheme [36] was used in the NCAR Community Climate Model version 3 (CCM3) radiation scheme [37]. The model configuration is summarized in Table 2.

In this study, the simulation periods of RegCM4 coupled with BATS and CLM3.5 (BATS and CLM, resp.) were November 1, 1991, to February 1, 2002, and November 1, 1989, to February 1, 2002, respectively. The period from January 1 , 1992, to December 31, 2001 (10 years), was considered in the analysis (Table 2). The months before 1992 were discarded as the initialization time. The $0.25^{\circ}$ gridded daily observed precipitation (CN05.1) [38] (hereafter referred to as CN05) was used for the evaluation of the simulation skills of

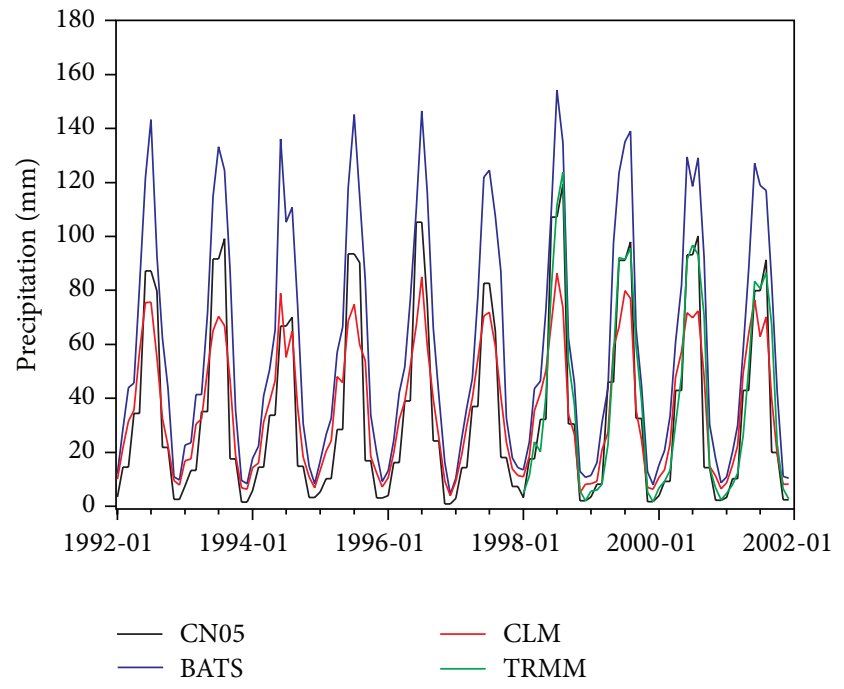

FIgURE 2: Monthly variations in the observed and simulated precipitation over the TP during 1992-2001.

BATS and CLM for precipitation. Monthly Tropical Rainfall Measurement Mission (TRMM) 3B42 V7 data with a spatial resolution of $0.25^{\circ} \times 0.25^{\circ}$ from 1998 to 2001 (4 years) were also used for the model's validation over the TP (ftp://disc2 .nascom.nasa.gov/data/TRMM/Gridded/3B43_V7/).

\section{Results and Discussion}

3.1. Monthly Precipitation Variation. Figure 2 shows the monthly precipitation variations of the observed and simulated results over the TP. It can be observed that both BATS and CLM simulated the monthly variations of the precipitation quite well, as indicated by the high correlation coefficients (above 0.92; Table 3). However, compared with the observed data, both CLM and BATS obviously overestimated the annual precipitation. The CLM-simulated precipitation, except for that in summer, was also higher than the observed data. The BATS- and CLM-simulated annual precipitation during 1992-2001 was $24.46 \mathrm{~mm}$ higher and $1.55 \mathrm{~mm}$ higher than the CN05 data, respectively. Although the correlation coefficients between the two model simulations and the observed data were approximately equal, CLM prominently reduced the bias and root mean square error (RMSE) when compared with the CN05 data. It is suggested that the 
TABLE 3: Statistical values between the simulated and observed precipitation.

\begin{tabular}{lcccc}
\hline & BATS_CN05 & CLM_CN05 & BATS_TRMM & CLM_TRMM \\
\hline Bias/mm & 24.46 & 1.55 & 20.39 & -3.41 \\
RMSE $/ \mathrm{mm}$ & 29.98 & 15.37 & 24.05 & 15.6 \\
Corr. & 0.93 & 0.92 & 0.98 & 0.93 \\
\hline
\end{tabular}

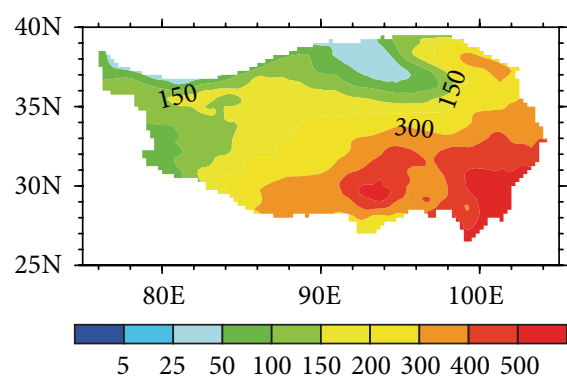

(a)

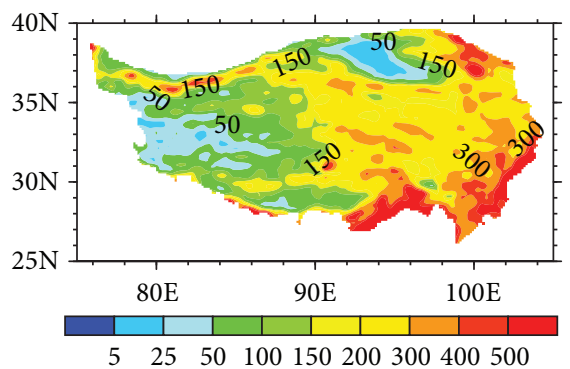

(d)

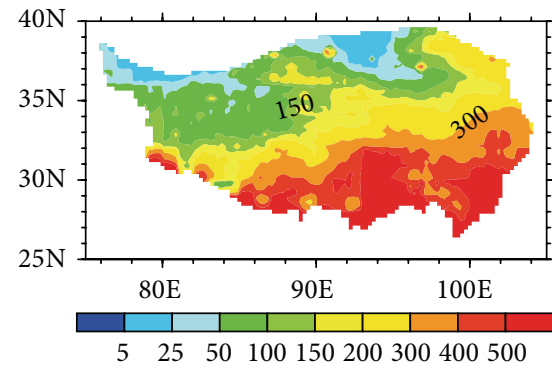

(b)

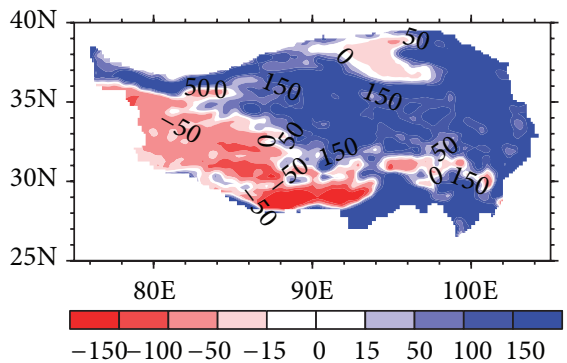

(e)

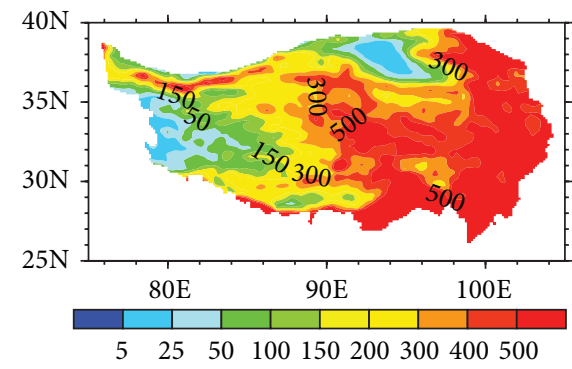

(c)

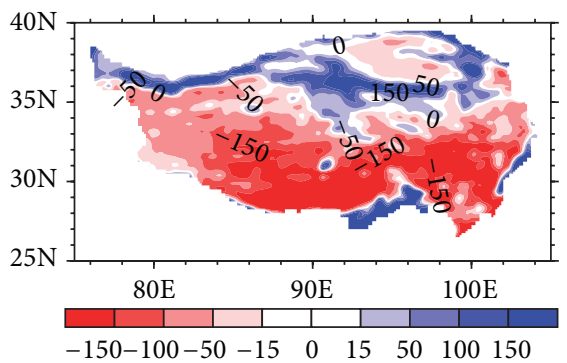

(f)

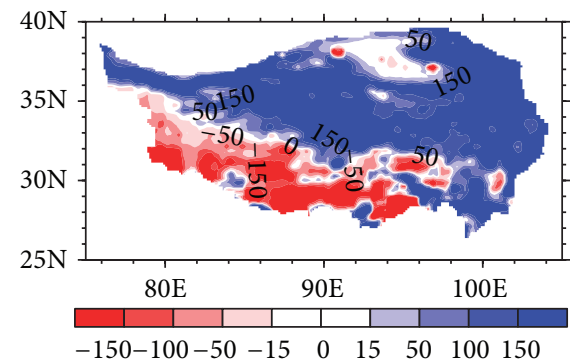

(g)

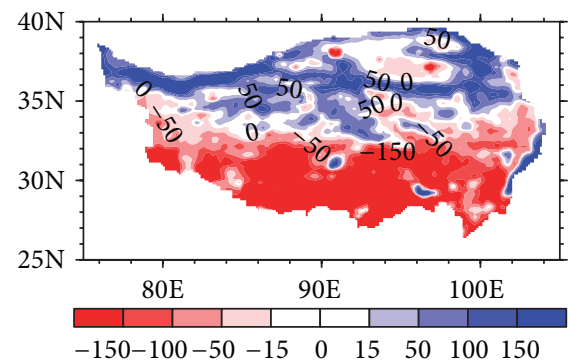

(h)

Figure 3: Summer precipitation distribution over the TP based on (a) CN05, (c) BATS, (d) CLM, (e) BATS minus CN05, and (f) CLM minus CN05 during 1992-2001 and (b) TRMM, (g) BATS minus TRMM, and (h) CLM minus TRMM during 1998-2001 (units: mm).

monthly precipitation using CLM was much more similar to the observed data compared with using BATS. During 1998-2001, the simulated data and TRMM data results were broadly consistent with those of CN05. However, the CLMsimulated monthly precipitation was slightly lower than that of the TRMM data. In addition, summer precipitation (June, July, and August) accounted for approximately 58\%-64\% and $48 \%-53 \%$ of the annual total precipitation in the observed and simulated results, respectively. Despite the low ratios in the simulated results, in general, summer precipitation largely contributed to the annual precipitation. Consequently, we mainly focus on the simulated summer precipitation in the $\mathrm{TP}$ in the following section.
3.2. Spatial Distribution of Summer Precipitation. The summer precipitation distributions simulated by the two models and observed by the CN05 data are shown in Figure 3. Summer precipitation in the TP was plentiful because of summer monsoons. The summer rainbands were found in the observed data, showing large amounts of precipitation in the southern and eastern TP. The maximum precipitation belt, with summer precipitation amounts over $500 \mathrm{~mm}$, was observed in the southeastern TP. The minimum precipitation belt, with summer precipitation less than $100 \mathrm{~mm}$, was located in the northern and western TP (Figure 3(a)). BATS and CLM are able to represent the basic spatial distributions of the summer precipitation (Figures 3(c) and 3(d)). Both 
TABLE 4: Statistical values between the simulated and observed summer mean daily precipitation during 1992-2001.

\begin{tabular}{lccc}
\hline & BATS_CN05 & CLM_CN05 & BATS_CLM \\
\hline Bias $/ \mathrm{mm} \cdot$ day $^{-1}$ & 0.95 & -0.67 & 2.86 \\
RMSE $/ \mathrm{mm} \cdot$ day $^{-1}$ & 1.02 & 0.79 & 1.66 \\
Corr. & 0.77 & 0.63 & 0.82 \\
\hline
\end{tabular}

models captured more subtle precipitation features compared to the observed data, particularly in the western TP. However, BATS overestimated the precipitation by $150 \mathrm{~mm}$, mainly in the central-eastern and northern plateau and in the eastern Himalayas; it underestimated the precipitation by $50 \mathrm{~mm}$ in the southwestern TP when compared to the CN05 data (Figure 3(e)). CLM significantly reduced the wet biases but enlarged the dry biases of BATS (Figure 3(f)). The pattern of overestimated northern precipitation and underestimated southern precipitation by the two models was consistent with the simulation results of Wang et al. [11] using RegCM3 in the TP. Larger deviations existed in the tall and large mountains, such as the Kunlun and Himalayan mountains, possibly because there are few observation stations over these regions; that is, the observed data are not very reliable [38]. The TP ten-year average summer precipitation of BATS was $87.4 \mathrm{~mm}$ (34.7\%) higher, but CLM was $61.6 \mathrm{~mm}$ (24.7\%) lower than that of the CN05 data (Table 4).

Further comparisons of the summer precipitation distribution during 1998-2001 based on TRMM and the two models are shown in Figures 3(b), 3(g), and 3(h). The distribution patterns of the difference between the two models and the TRMM data were generally consistent with those of CN05. The summer precipitation remained lower in the southern TP and higher in the northern TP. Overall, the differences between CLM and the TRMM data were smaller than those of CLM and the CN05 data. There was little difference between the two models in the Qaidam Basin and in the western TP. However, BATS-simulated precipitation in other regions was obviously higher than that of CLM (Figures 3(g) and $3(\mathrm{~h})$ ). This further illustrated that the capability of CLM in simulating summer precipitation in the TP was improved to some extent.

3.3. Interpretations of the Results. The improvement in the RegCM4 experiment by using CLM is due to several changes to the model, such as the vegetation types, vegetated cover, soil types, and the formulation of the evaporation from soil [28]. Figure 4 shows the difference distributions of the summer surface soil moisture, evapotranspiration, sensible heat flux, and air temperature between BATS and CLM. Differences in the simulated precipitation tended to cause differences in the soil moisture [39]. The differences in the surface soil moisture between the BATS and CLM experiments are apparent in Figure 4(a). The positive/negative differences in the simulated precipitation between BATS and CLM largely corresponded to the positive/negative differences in the soil moisture between BATS and CLM (see Figures 3 and 4(a)). In most parts of the TP, the soils of BATS were much wetter than those of CLM. Some studies suggest that CLM has an eminent dry bias compared with other land-surface models, partly because it tends to simulate low contributions from transpiration and high contributions from soil and canopy evaporation to the mean global evapotranspiration $[28,39,40]$. Steiner et al. [39] analyzed the effect of soil texture on soil moisture and precipitation and concluded that although the soil texture could trigger land-atmosphere coupling differences between the two models, the physical parameterizations in CLM3 allow the soil moisture changes to interact effectively with the atmosphere. The soil moisture-precipitation feedback is an important element of Earth's climate system (e.g., [41-43]). Higher soil moisture can lead to higher evapotranspiration, and the increased evapotranspiration adds more moisture to the atmosphere, and the added moisture likely leads to higher precipitation. The summer evapotranspiration simulated by BATS was $\sim 20 \mathrm{~mm}$ higher than that of CLM, except in the Qaidam Basin and in the western TP (Figure 4(b)). The overestimation of the precipitation in BATS was partly due to the local increase in the evapotranspiration (Figures 3 and $4(\mathrm{~b}))$.

The summer latent flux and evapotranspiration have similar patterns and the same magnitudes (not shown). The summer sensible heat flux simulated by BATS was smaller than that of CLM at the edge of the TP (Figure 4(c)). In the remaining areas, particularly in the southwestern TP, the sensible heat flux from BATS was dramatically higher than that from CLM. It can be observed that the atmospheric heating effect (sensible heat flux + latent heat flux) simulated by BATS was strong. A recent study indicated that there is a close relationship between sensible heat flux in late spring and early summer in the Central TP and the precipitation from June to September in Central and Eastern Tibet. Specifically, greater sensible heat flux in the Central TP during May caused stronger cyclonic flow and low vortices, resulting in more precipitation during the summer monsoon over the eastern plateau [44]. The difference distributions of the summer air temperature and evapotranspiration have similar patterns but opposite signs (Figure 4(d)). Specifically, the areas with underestimated evapotranspiration corresponded to the areas with overestimated temperature by BATS, such as the Qaidam Basin and the Qangtang Plateau, and vice versa. The TP average summer temperature of BATS was $0.53^{\circ} \mathrm{C}$ lower than that of CLM. Understanding the mechanisms of precipitation changes is fundamentally difficult because there are complex relationships between evapotranspiration, moisture flux convergence, and soil moisture. When precipitation increases, soil moisture increases. As a result, evaporation (surface latent heat flux) increases at the expense of the surface sensible heat flux. Cooler near-surface air temperatures are induced, and moisture is added to the atmosphere. These processes alter the modes of the surface pressure and wind fields and further change the moisture convergence and precipitation. Moreover, these relationships vary spatially and temporally, which increase the difficulties of analyses [22].

There are three water vapor channels for climatological summer precipitation over the TP [45]. The first channel is the Indian summer monsoon. The strong southwesterly water flow combined with the Somali jet stream transports moisture from the Arabian Sea and the Bay of Bengal to the 


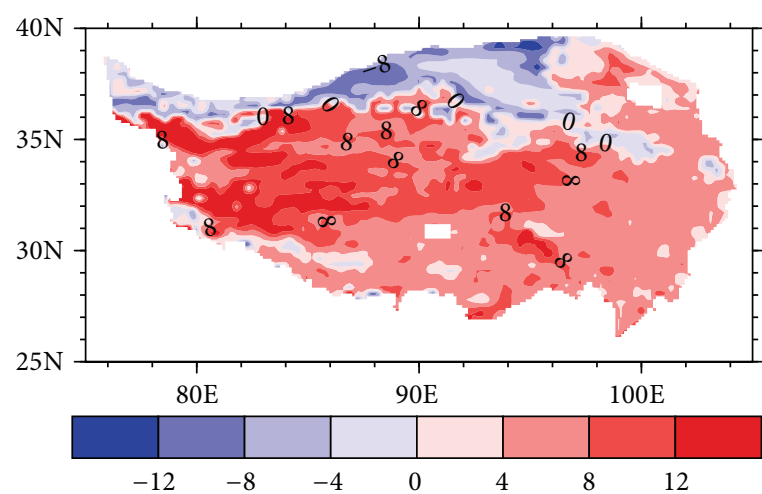

(a)

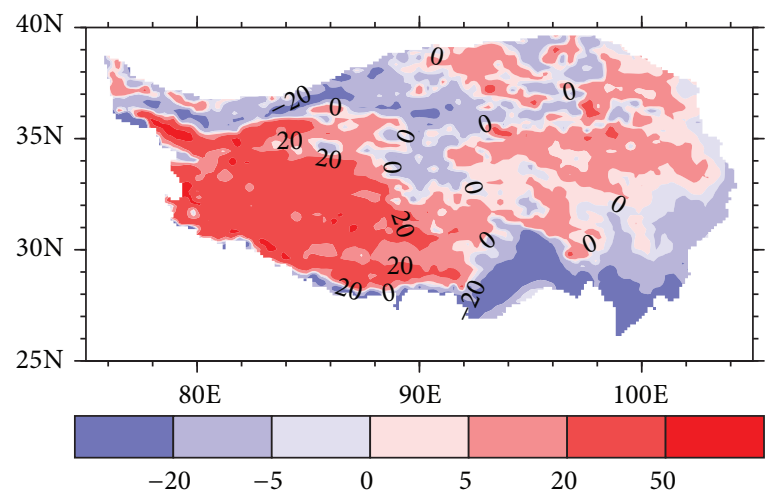

(c)

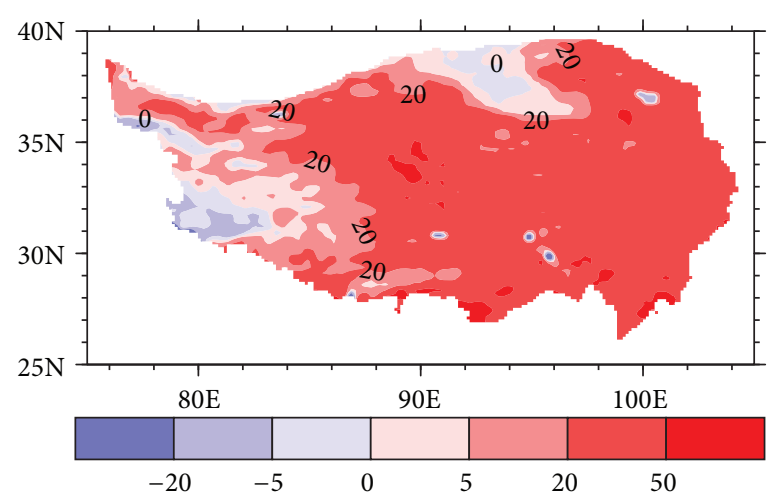

(b)

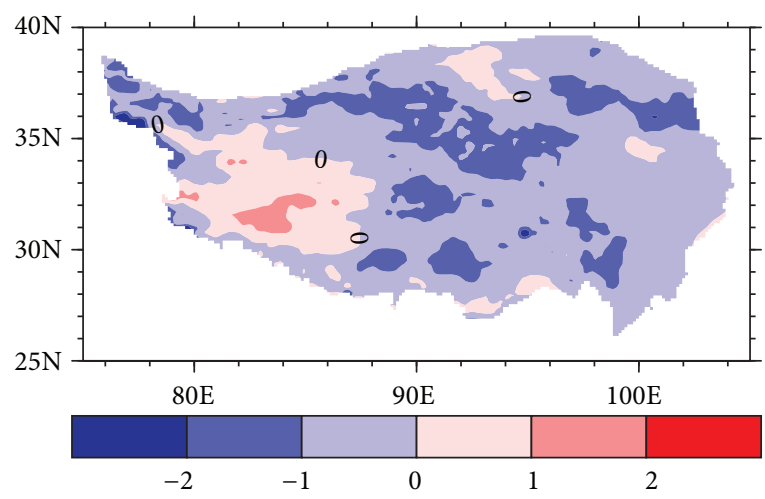

(d)

FIGURE 4: (a) The summer surface soil moisture difference between the BATS and CLM experiments (units: $\mathrm{kg} \cdot \mathrm{m}^{-2}$ ). (b) The same as (a) but for evapotranspiration (ET) (units: $\mathrm{mm}$ ). (c) The same as (a) but for sensible heat flux (SHF) (units: W $\cdot \mathrm{m}^{-2}$ ). (d) The same as (a) but for $2 \mathrm{~m}$ air temperature (units: ${ }^{\circ} \mathrm{C}$ ) during 1992-2001.

southeastern TP. The second channel is the midlatitude westerlies, which split into two branches in the summer near the western TP. Water vapor carried by the southern branch of the westerly flow moves southward and then turns to the east at approximately $28^{\circ} \mathrm{N}$; it ultimately combines with the southwesterlies over the Indian Ocean. The third channel is water vapor transport from the northern boundary; the contribution of this source is very weak and nearly negligible. This third channel only has an impact on summer precipitation over the northern TP. The distributions of the summer wind field and air temperature at the $500 \mathrm{hPa}$ and $200 \mathrm{hPa}$ levels from the ERA40 data and the two models are shown in Figure 5. The ERA40 data showed much higher temperatures at $500 \mathrm{hPa}$ in the southern TP (Figure 5(A)), resulting in a stronger Indian summer monsoon [45]. The locations of the Indian low pressure simulated by BATS and CLM were slightly different from those suggested by the ERA40 data. BATS clearly simulated the TP thermal low and upper-level warm high pressure (Figures 5(B) and 5(E)). These locations also corresponded to low values of sensible heat flux and air temperature when using CLM (Figure 4). The thermal low can transport water vapor from the westerlies and the southwesterlies into the southern TP and its surroundings, resulting in more BATS-simulated precipitation. However, the strength and range of the thermal low of CLM were smaller than those of BATS. These findings suggest that the configuration of the thermal low pressure in relation to the warm high pressure between the 500 and $200 \mathrm{hPa}$ levels, as generated by BATS, pulled in the surrounding water vapor and caused strong convergence and convection due to its unusually strong heating effect.

To determine the causes of the differences in RegCM4's skill in simulating precipitation when coupled with the two land-surface schemes, differences in the profiles of wind $(U, V)$, temperature $(T)$, vertical velocity $(W)$, geopotential height $(H)$, mixing ratio $(Q)$, and relative humidity $(\mathrm{RH})$ over the TP were analyzed (Figure 6). At various heights of the troposphere, there were some differences in the zonal and meridional winds between the two models. The zonal wind simulated by CLM throughout the entire troposphere was westerly, with an average wind speed of $3.18 \mathrm{~m} / \mathrm{s}$. Thus, the water vapor transported by the easterly wind from the Pacific Ocean to the eastern TP became dry after passing through mainland China. BATS simulated westerly wind $(0.97 \mathrm{~m} / \mathrm{s})$ and strong easterly wind $(5.89 \mathrm{~m} / \mathrm{s})$ in the middle/lower and upper troposphere, respectively (Figure 6(a)). Regarding the meridional wind, above $250 \mathrm{hPa}$, northerly wind was simulated by the two models, especially by BATS. However, southerly wind was simulated by the two models below $300 \mathrm{hPa}$. The wind in BATS was slightly strong 


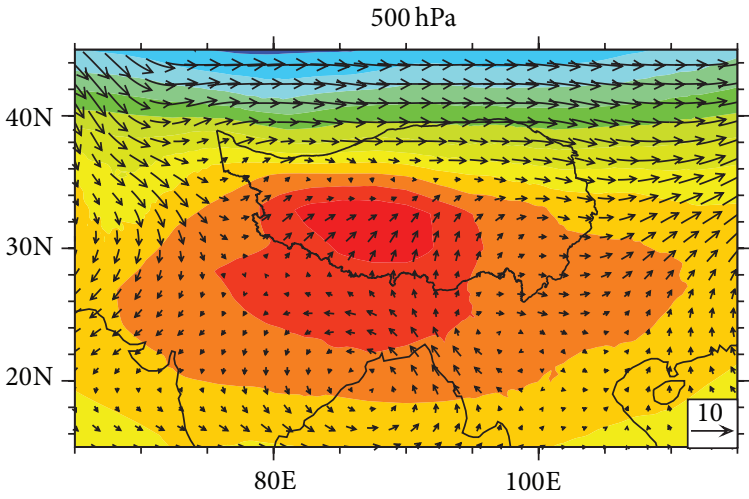

(A) ERA40

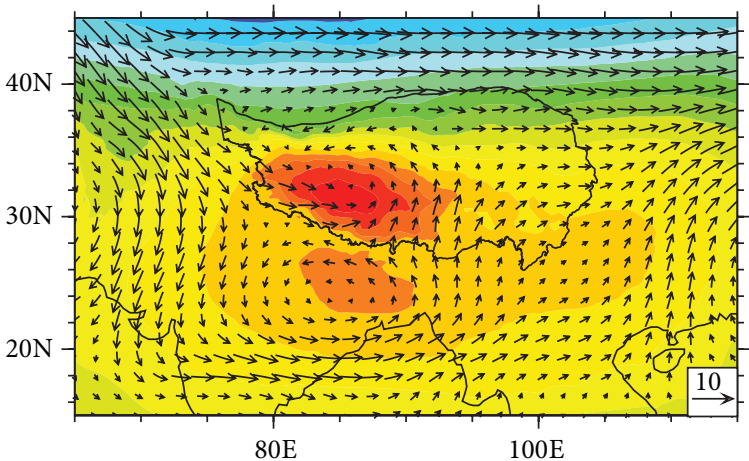

(B) BATS

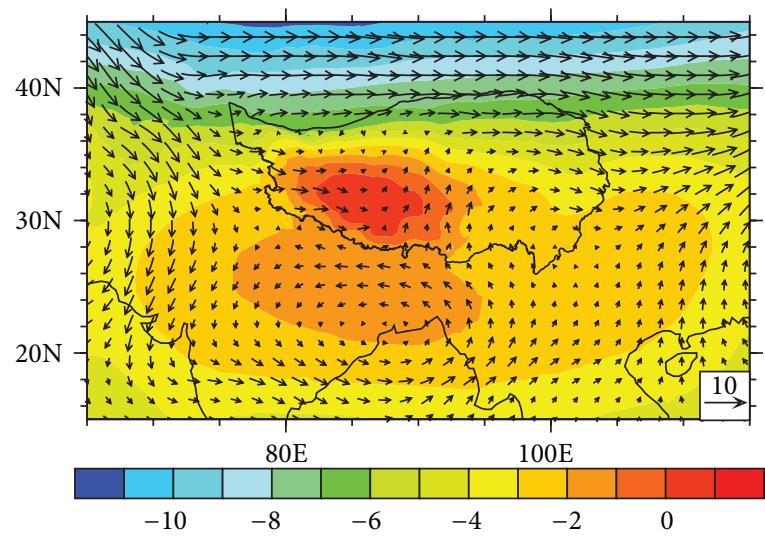

(C) CLM

(a)

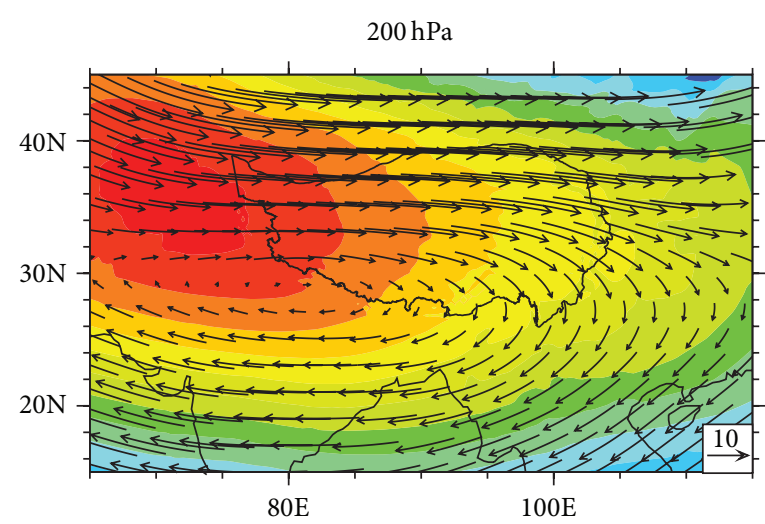

(D) ERA40

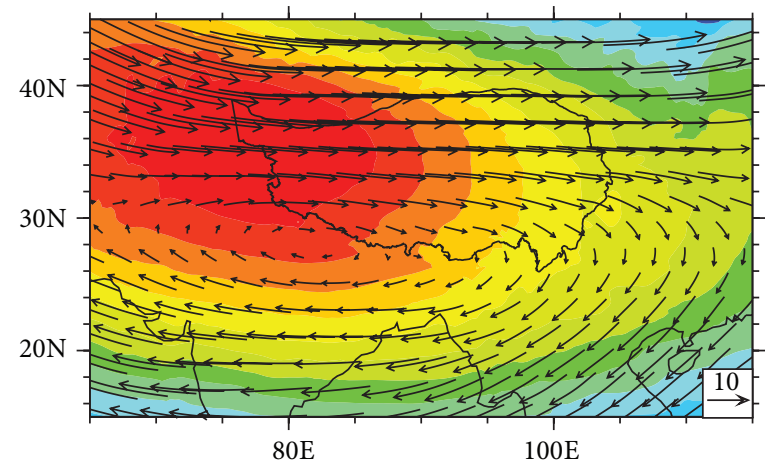

(E) BATS

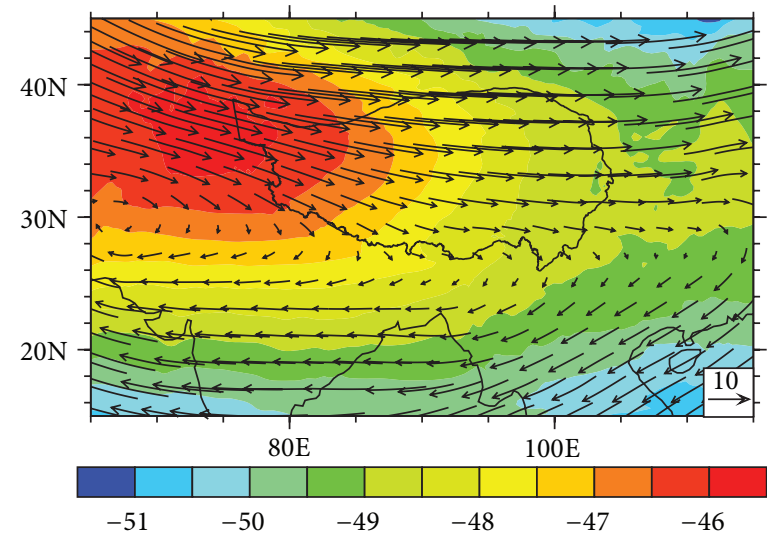

(F) CLM

(b)

Figure 5: The summer mean wind (units: $\mathrm{m} / \mathrm{s}$ ) and temperature (units: ${ }^{\circ} \mathrm{C}$ ) distributions at $500 \mathrm{hPa}(\mathrm{a})$ and $200 \mathrm{hPa}$ (b) over the TP during 1992-2001. (A) and (D) represent ERA40; (B) and (E) represent BATS; and (C) and (F) represent CLM.

below $400 \mathrm{hPa}$ (Figure 6(b)) and transported Indian Ocean water vapor that directly contributed to more precipitation in the southern TP (Figures 3(e) and 3(g)). The differences in the atmospheric temperatures at various heights, as simulated by the two models, were not negligible. The temperatures in the middle/lower troposphere were warmer and those above $150 \mathrm{hPa}$ were colder in BATS than in CLM (Figure 6(c)). The results showed that BATS simulated the atmosphere as unstable and prone to strong air convection and ascending motion. The vertical velocities simulated by the two models, particularly by BATS, were both negative and were characterized by upward vertical motion (Figure 6(d)). Accordingly, such upward vertical motion in BATS modified the geopotential heights. In BATS, the geopotential heights below $500 \mathrm{hPa}$ were low, however, they increased with the height of troposphere and reached a maximum at $250 \mathrm{hPa}$. 


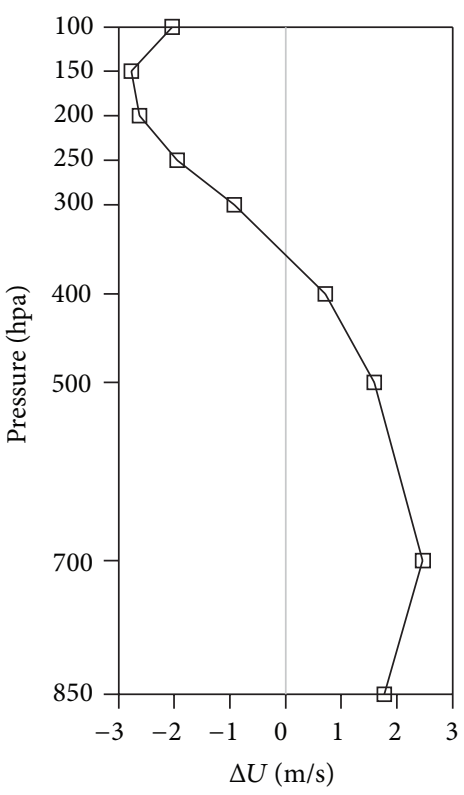

(a)

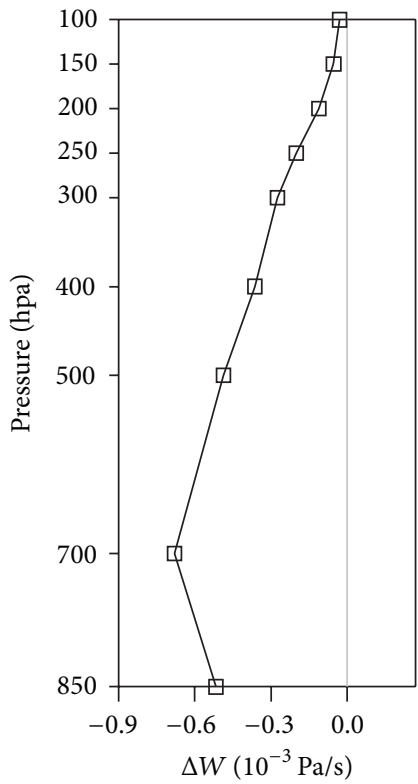

(d)

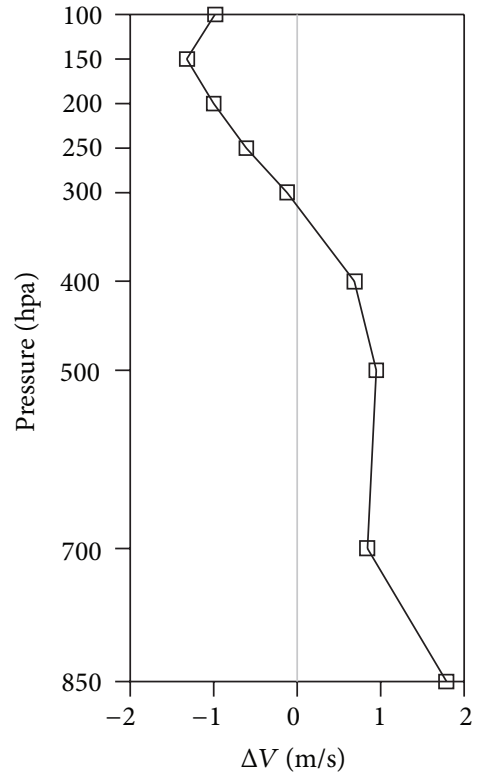

(b)

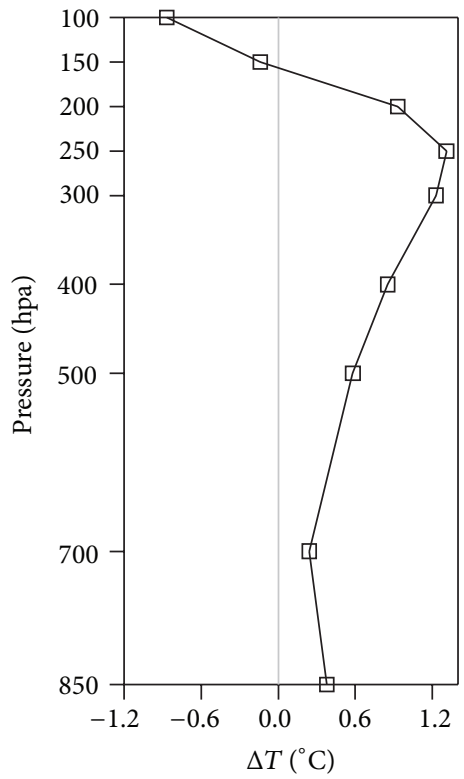

(c)

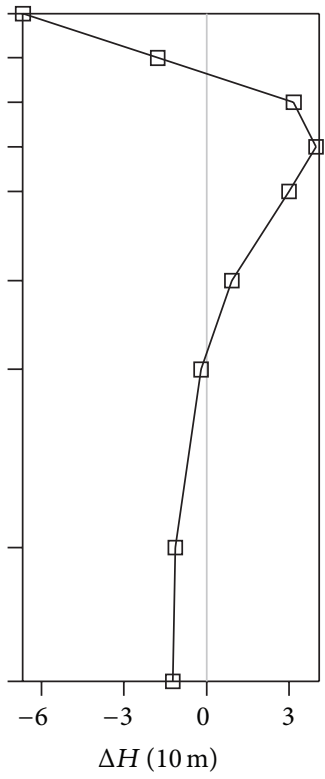

(e)

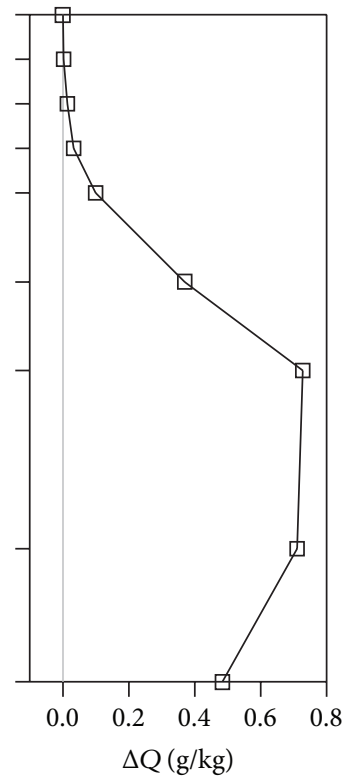

(f)

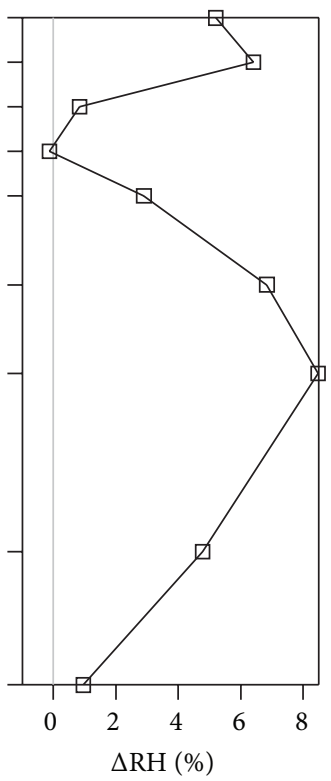

(g)

FIGURE 6: The profiles of the 10-year summer mean differences between BATS and CLM for (a) zonal wind $U$, (b) meridional wind $V$, (c) air temperature $T$, (d) vertical velocity $W$, (e) geopotential height $H$, (f) water vapor mixing ratio $Q$, and (g) relative humility RH over the TP.

Then, the heights gradually decreased with the height of the troposphere (Figure 6(e)). The mixing ratio and relatively humidity in the lower to midtroposphere were overestimated by BATS (Figures 6(f) and 6(g)). The above results showed that BATS simulated the lower troposphere as warm and humid and simulated the upper troposphere $(\sim 150 \mathrm{hPa})$ as cold; thus, the stability decreased and more convective precipitation occurred. This result is consistent with the results from previous studies using RegCM4 driven by ERA boundary conditions [20].

A hypothesis proposed by Eltahir [46] suggests that a positive feedback mechanism exists between soil moisture and rainfall via the control of soil moisture on the surface albedo and Bowen ratio. Numerical experiments developed by Zheng and Eltahir [47] support the proposed hypothesis and emphasize the importance of the radiative and dynamic feedbacks in regulating the rainfall anomalies that result from soil moisture anomalies. Therefore, higher soil moisture increases the latent heat flux, which tends to increase the moist entropy flux per unit mass of air and the amount of convective available potential energy in the boundary layer. These processes likely increase the frequency and magnitude of convective precipitation events [41]. Moreover, recent research on satellite observations shows that the probability 


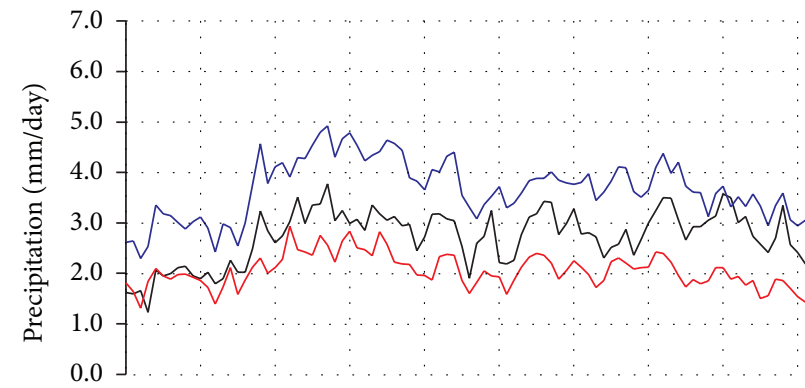

(a)

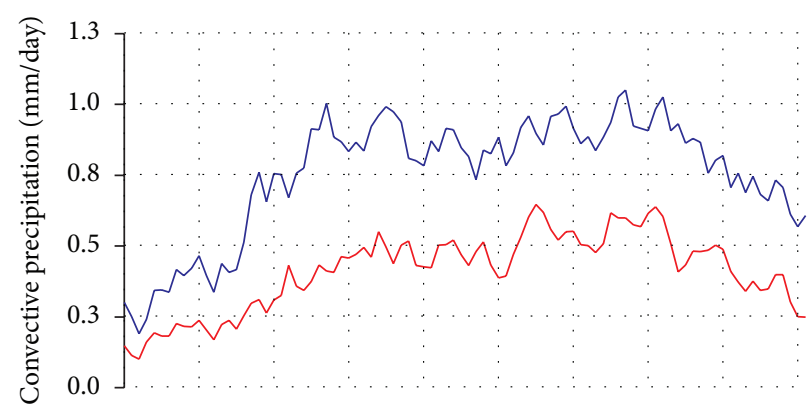

(b)

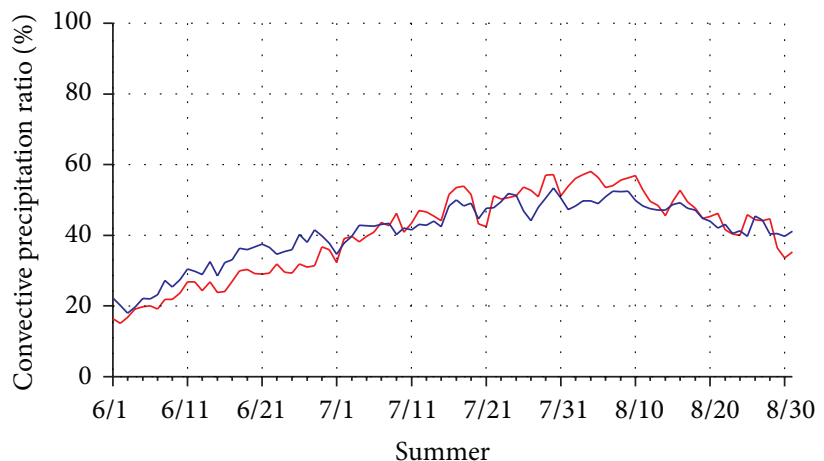

CN05
- CLM
- BATS

(c)

FIGURE 7: The observed and simulated summer daily precipitation (a), convective precipitation (b), and convective precipitation ratio (c) over the TP during 1992-2001. The ratio is defined as the ratio of the summer convective precipitation to the summer precipitation in the two simulations.

of convective initiation is enhanced over strong soil moisture gradients compared with uniform soil moisture conditions [48]. The summer average daily precipitation for the observation data and the two models are shown in Figure 7. The two models adequately simulated the daily precipitation variations, as indicated by the correlation coefficients above 0.63 (the values exceeded the $99 \%$ significance test). However, the BATS- and CLM-simulated summer precipitation was evidently $1.02 \mathrm{~mm} /$ day higher and $0.67 \mathrm{~mm}$ /day smaller than the CN05 data, respectively (Table 4). These results consistently matched the results of monthly and annual precipitation (Figures 2 and 3). Recently, the effect of local convection on precipitation over the TP has increasingly been the focus of research $[49,50]$. The summer convective precipitation events simulated by the two models were only compared with each other because of the lack of observations (Figure 7(b)). The BATS-simulated summer convective precipitation, which was affected by the strong upward vertical movement, was $0.68 \mathrm{~mm} /$ day higher than that of CLM. Additionally, the variations in the summer convective precipitation simulated by both models were largely consistent with those of the total summer precipitation when comparing Figures 7(a) and 7(b). The correlation coefficients of the summer convective precipitation and summer precipitation in BATS and CLM were 0.79 and 0.51 , respectively. Specifically, the BATS-simulated summer convective precipitation accounted for more of the total summer precipitation. That is part of reason summer precipitation of BATS was overestimated. In addition, we also calculated the ratios of convective precipitation to the precipitation of the two models. Both ratios were very similar because the two models adopted the same Grell cumulus convective parameterization scheme (Figure 7(c)). Yang et al. [50] demonstrated that TP precipitation occurred frequently and very locally, except on several days with very strong monsoonal precipitation. According to the summer (May to September) precipitation and $\delta^{18} \mathrm{O}$ data, precipitation that formed directly by the ocean air mass vapor accounts for a maximum of $32 \%$ of the total precipitation, while precipitation that formed by local, evaporated water accounts for a minimum of $46.9 \%$ of the total precipitation [51]. Similarly, recent research reported that a large portion of the precipitation in alpine meadows was due to evaporated water, and the mean contribution was $39.57 \%$ using stable isotopes (delta $(d)$-excess value) from June to September in the alpine ecosystems of the eastern TP [52]. Furthermore, the CLM-simulated convective precipitation was somewhat similar to the results of these studies.

\section{Conclusions}

To investigate the responses of precipitation simulations to two land-surface schemes (BATS and CLM3.5) in a regional 
climate model over the TP, two groups of ten-year climate simulations from RegCM4 were analyzed and compared with the same domain, ICBC, cumulus convective parameterization scheme, and spatial resolution. The results showed that the land-surface processes strongly affected the precipitation simulations. The CLM-simulated monthly precipitation was much more similar, but slightly lower, than the observed data. However, the monthly precipitation of BATS was higher than the observed values. BATS and CLM both successfully simulated the distributions of the summer precipitation belt. Compared to the CN05 data, BATS evidently overestimated the summer precipitation in the central-eastern TP, the eastern Himalayas, and the northern TP, whereas it underestimated the summer precipitation in the southwestern TP. Because of the relatively more sophisticated land-surface representation, CLM significantly reduced the overestimated precipitation areas and magnitudes of BATS, but it did not greatly improve for the underestimated precipitation. As for the ten-year average, BATS and CLM overestimated and underestimated the summer precipitation by $87.4 \mathrm{~mm}(34.7 \%)$ and $61.6 \mathrm{~mm}$ (24.7\%), respectively, compared to the CN05 data. High soil moisture, evapotranspiration and heating effects simulated by BATS led to strong thermal low pressure in the middle/lower troposphere and warm high pressure in the upper troposphere over the TP. These characteristics, along with the warm and humid lower atmosphere and cold upper atmosphere, generated strong unstable air convection, convergence, and upward motion. Thus, the convective precipitation had a greater contribution to the total summer precipitation, and the summer precipitation of BATS was overestimated.

\section{Conflict of Interests}

The authors declare that there is no conflict of interests regarding the publication of this paper.

\section{Acknowledgments}

The authors acknowledge the support by the Innovation Research Group of NSFC (41121001), the "Strategic Priority Research Program (B)" of CAS (XDB03030204), the State Key Laboratory of Cryospheric Sciences (SKLCS-ZZ-201302-07), CAREERI, CAS, the International Innovative Group Project of CAS (Y42AC71001), the National Natural Science Foundation of China (41075007), and the National Key Basic Research Program of China (2010CB951404). They also appreciate the Supercomputing Center, CAREERI, CAS, for help with model simulations. Thanks are due to Dr. Jia Wu for providing the CN05.1 precipitation data. The authors appreciate the reviewers and editors for the positive remarks and insightful comments as well as suggestions.

\section{References}

[1] G. Wu, Y. Liu, B. He, Q. Bao, A. Duan, and F.-F. Jin, "Thermal controls on the asian summer monsoon," Scientific Reports, vol. 2, article 404, 2012.

[2] X. Xu, C. Lu, Y. Ding, X. Shi, Y. Guo, and W. Zhu, "What is the relationship between China summer precipitation and the change of apparent heat source over the Tibetan Plateau?" Atmospheric Science Letters, vol. 14, no. 4, pp. 227-234, 2013.

[3] X. Xu, C. Lu, X. Shi, and S. Gao, "World water tower: an atmospheric perspective," Geophysical Research Letters, vol. 35, no. 20, pp. 1-5, 2008.

[4] F. Giorgi and M. R. Marinucci, "An investigation of the sensitivity of simulated precipitation to model resolution and its implications for climate studies," Monthly Weather Review, vol. 124, no. 1, pp. 148-166, 1996.

[5] J. Feng and C. Fu, "Inter-comparison of 10-year precipitation simulated by several RCMs for Asia," Advances in Atmospheric Sciences, vol. 23, no. 4, pp. 531-542, 2006.

[6] D. Caya and S. Biner, "Internal variability of RCM simulations over an annual cycle," Climate Dynamics, vol. 22, no. 1, pp. 3346, 2004.

[7] X. J. Gao, Y. Shi, and F. Giorgi, "A high resolution simulation of climate change over China," Science China Earth Sciences, vol. 54, no. 3, pp. 462-472, 2011.

[8] F. Giorgi, E. Coppola, F. Solmon et al., "RegCM4: model description and preliminary tests over multiple CORDEX domains," Climate Research, vol. 52, no. 1, pp. 7-29, 2012.

[9] L. O. Mearns, R. Arritt, S. Biner et al., "The north american regional climate change assessment program overview of phase I results," Bulletin of the American Meteorological Society, vol. 93, no. 9, pp. 1337-1362, 2012.

[10] H. Matthes, A. Rinke, P. A. Miller, P. Kuhry, K. Dethloff, and A. Wolf, "Sensitivity of high-resolution Arctic regional climate model projections to different implementations of land surface processes," Climatic Change, vol. 111, no. 2, pp. 197-214, 2012.

[11] X. Wang, M. Yang, G. Wan, X. Chen, and G. Pang, "QinghaiXizang (Tibetan) Plateau climate simulation using the regional climate model RegCM3," Climate Research, vol. 57, no. 3, pp. 173-186, 2013.

[12] F. Giorgi, M. R. Marinucci, G. T. Bates, and G. de Canio, "Development of a second-generation regional climate model (RegCM2). Part II: convective processes and assimilation of lateral boundary conditions," Monthly Weather Review, vol. 121, no. 10, pp. 2814-2832, 1993.

[13] A. Arakawa, "The cumulus parameterization problem: past, present, and future," Journal of Climate, vol. 17, no. 13, pp. 24932525, 2004.

[14] Y. Yang and M. Yang, "Application of regional climate model(RegCM3) to the Tibetan Plateau: sensitivity experiments for cumulus convection parameterization scheme," Journal of Glaciology and Geocryology, vol. 30, no. 2, pp. 250-258, 2008 (Chinese).

[15] X. Luo, M. Yang, X. Wang, G. Wan, X. Chen, and X. Liang, "Simulation influences of summer precipitation by two cumulus parameterization schemes over Qinghai-Xizang plateau," Plateau Meteorology, vol. 33, no. 2, pp. 313-322, 2014 (Chinese).

[16] E. Yu, H. Wang, Y. Gao, and J. Sun, "Impacts of cumulus convective parameterization schemes on summer monsoon precipitation simulation over China," Acta Meteorologica Sinica, vol. 25, no. 5, pp. 581-592, 2011.

[17] X. Gao, Y. Luo, W. Lin, Z. Zhao, and F. Giorgi, "Simulation of effects of land use change on climate in China by a regional climate model," Advances in Atmospheric Sciences, vol. 20, no. 4, pp. 583-592, 2003.

[18] F. Giorgi, R. Francisco, and J. Pal, "Effects of a subgrid-scale topography and land use scheme on the simulation of surface climate and hydrology. Part I: effects of temperature and water 
vapor disaggregation," Journal of Hydrometeorology, vol. 4, no. 2, pp. 317-333, 2003.

[19] X. Gao, Y. Xu, Z. Zhao, J. Pal, and F. Giorgi, "Impacts of horizontal resolution and topography on the numerical simulation of East Asian precipitation," Chinese Journal of Atmospheric Sciences, vol. 30, no. 2, pp. 185-192, 2006 (Chinese).

[20] J.-H. Park, S.-G. Oh, and M.-S. Suh, "Impacts of boundary conditions on the precipitation simulation of RegCM4 in the CORDEX East Asia domain," Journal of Geophysical Research D: Atmospheres, vol. 118, no. 4, pp. 1652-1667, 2013.

[21] L. Sun, G. Wu, and S. Sun, "Numerical simulations of effects of land surface processes on climate-implementing of SSiB in IAP/LASG AGCM and its performance," Acta Meteorologica Sinica, vol. 15, no. 2, pp. 160-177, 2001 (Chinese).

[22] M. Kanamitsu and K. C. Mo, "Dynamical effect of land surface processes on summer precipitation over the Southwestern United States," Journal of Climate, vol. 16, no. 3, pp. 496-509, 2003.

[23] L. Chen, Z. Ma, and X. Fan, "A comparative study of two land surface schemes in WRF model over Eastern China," Journal of Tropical Meteorology, vol. 18, no. 4, pp. 445-456, 2012.

[24] J. Zhou and X. Xie, "The effects of the land-surface process parameterization of the RegCM4 on climate simulation in East Asia," Acta Meteorologica Sinica, vol. 70, no. 6, pp. 1312-1326, 2012.

[25] R. E. Dickinson, A. Henderson-Sellers, and P. J. Kennedy, "Biosphere-atmosphere transfer scheme (BATS) version le as coupled to the NCAR community climate model," Tech. Rep. NCAR.TN-387+STR, National Center for Atmospheric Research Tech Note, Boulder, Colo, USA, 1993.

[26] M. Wilson, The construction and use of land surface information in a general circulation climate model [Doctoral dissertation], University of Liverpool, 1984.

[27] K. Oleson, Y. Dai, G. Bonan et al., "Technical description of the community land model (CLM)," NCAR Technical Note NCAR/ TN-461+STR, 2004.

[28] K. W. Oleson, G.-Y. Niu, Z.-L. Yang et al., "Improvements to the community land model and their impact on the hydrological cycle," Journal of Geophysical Research G: Biogeosciences, vol. 113, no. 1, Article ID G01021, 2008.

[29] G. B. Bonan, S. Levis, L. Kergoat, and K. W. Oleson, "Landscapes as patches of plant functional types: an integrating concept for climate and ecosystem models," Global Biogeochemical Cycles, vol. 16, article 1021, no. 2, 2002.

[30] P. J. Lawrence and T. N. Chase, "Representing a new MODIS consistent land surface in the Community Land Model (CLM 3.0)," Journal of Geophysical Research G: Biogeosciences, vol. 112, no. 1, Article ID G01023, 2007.

[31] P. E. Thornton and N. E. Zimmermann, "An improved canopy integration scheme for a land surface model with prognostic canopy structure," Journal of Climate, vol. 20, no. 15, pp. 39023923, 2007.

[32] G.-Y. Niu, Z.-L. Yang, R. E. Dickinson, and L. E. Gulden, "A simple TOPMODEL-based runoff parameterization (SIMTOP) for use in global climate models," Journal of Geophysical Research D: Atmospheres, vol. 110, no. 21, Article ID D21106, 2005.

[33] G.-Y. Niu and Z.-L. Yang, "Effects of frozen soil on snowmelt runoff and soil water storage at a continental scale," Journal of Hydrometeorology, vol. 7, no. 5, pp. 937-952, 2006.

[34] G.-Y. Niu, Z.-L. Yang, R. E. Dickinson, L. E. Gulden, and H. Su, "Development of a simple groundwater model for use in climate models and evaluation with Gravity Recovery and Climate Experiment data," Journal of Geophysical Research D, vol. 112, no. 7, Article ID D07103, 2007.

[35] G. A. Grell, "Prognostic evaluation of assumptions used by cumulus parameterizations," Monthly Weather Review, vol. 121, no. 3, pp. 764-787, 1993.

[36] A. A. M. Holtslag, E. I. F. de Bruijn, and H.-L. Pan, "A high resolution air mass transformation model for short-range weather forecasting," Monthly Weather Review, vol. 118, no. 8, pp. 1561-1575, 1990.

[37] J. Kiehl, J. Hack, G. Bonan et al., Description of the NCAR Community Climate Model(CCM3), NCAR Technical Note NCAR/ TN-420+STP, 1996.

[38] J. Wu and X.-J. Gao, "A gridded daily observation dataset over China region and comparison with the other datasets," Chinese Journal of Geophysics, vol. 56, no. 4, pp. 1102-1111, 2013 (Chinese).

[39] A. L. Steiner, J. S. Pal, S. A. Rauscher et al., "Land surface coupling in regional climate simulations of the West African monsoon," Climate Dynamics, vol. 33, no. 6, pp. 869-892, 2009.

[40] P. J. Lawrence and T. N. Chase, "Climate impacts of making evapotranspiration in the Community Land Model (CLM3) consistent with the Simple Biosphere Model (SiB)," Journal of Hydrometeorology, vol. 10, no. 2, pp. 374-394, 2009.

[41] J. S. Pal and E. A. B. Eltahir, "Pathways relating soil moisture conditions to future summer rainfall within a model of the landatmosphere system," Journal of Climate, vol. 14, no. 6, pp. 12271242, 2001.

[42] R. D. Koster, M. J. Suarez, R. W. Higgins, and H. M. van den Dool, "Observational evidence that soil moisture variations affect precipitation," Geophysical Research Letters, vol. 30, no. 5, 2003.

[43] S. I. Seneviratne, T. Corti, E. L. Davin et al., "Investigating soil moisture-climate interactions in a changing climate: a review," Earth-Science Reviews, vol. 99, no. 3-4, pp. 125-161, 2010.

[44] L. Wen, P. Cui, L. Xiang, and H. Fang, "The relationship between the difference of air and ground and the precipiation during June to September in Eastern Qinghai-Xizang Platerau," Journal of Glaciology and Geocryology, vol. 33, no. 2, pp. 300-308, 2011 (Chinese).

[45] L. Feng and T. Zhou, "Water vapor transport for summer precipitation over the Tibetan Plateau: multidata set analysis," Journal of Geophysical Research D: Atmospheres, vol. 117, no. 20, Article ID D20114, 2012.

[46] E. A. B. Eltahir, "A soil moisture-rainfall feedback mechanism 1. Theory and observations," Water Resources Research, vol. 34, no. 4, pp. 765-776, 1998.

[47] X. Zheng and E. A. B. Eltahir, "A soil moisture-rainfall feedback mechanism 2. Numerical experiments," Water Resources Research, vol. 34, no. 4, pp. 777-785, 1998.

[48] C. M. Taylor, A. Gounou, F. Guichard et al., "Frequency of sahelian storm initiation enhanced over mesoscale soil-moisture patterns," Nature Geoscience, vol. 4, no. 7, pp. 430-433, 2011.

[49] K. Yang, T. Koike, H. Fujii et al., "The daytime evolution of the atmospheric boundary layer and convection over the Tibetan Plateau: observations and simulations," Journal of the Meteorological Society of Japan, vol. 82, no. 6, pp. 1777-1792, 2004.

[50] M. Yang, T. Yao, X. Gou, H. Wang, and H. Tang, "The spatially heterogeneous distribution of precipitation of the Anduo area, Tibetan Plateau, in summer 1998," Hydrological Sciences Journal, vol. 52, no. 4, pp. 645-653, 2007. 
[51] M. Yang, T. Yao, H. Wang, L. Tian, and X. Gou, "Estimating the criterion for determining water vapour sources of summer precipitation on the northern Tibetan Plateau," Hydrological Processes, vol. 20, no. 3, pp. 505-513, 2006.

[52] W. Zhang, B. Cheng, Z. Hu et al., "Using stable isotopes to determine the water sources in alpine ecosystems on the east Qinghai-Tibet plateau, China," Hydrological Processes, vol. 24, no. 22, pp. 3270-3280, 2010 

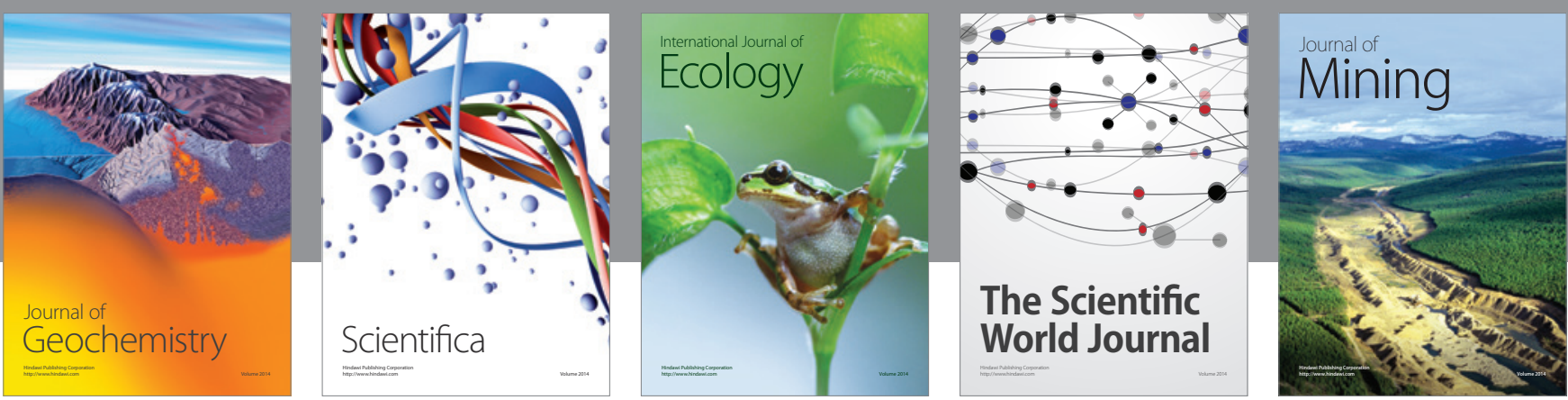

The Scientific World Journal
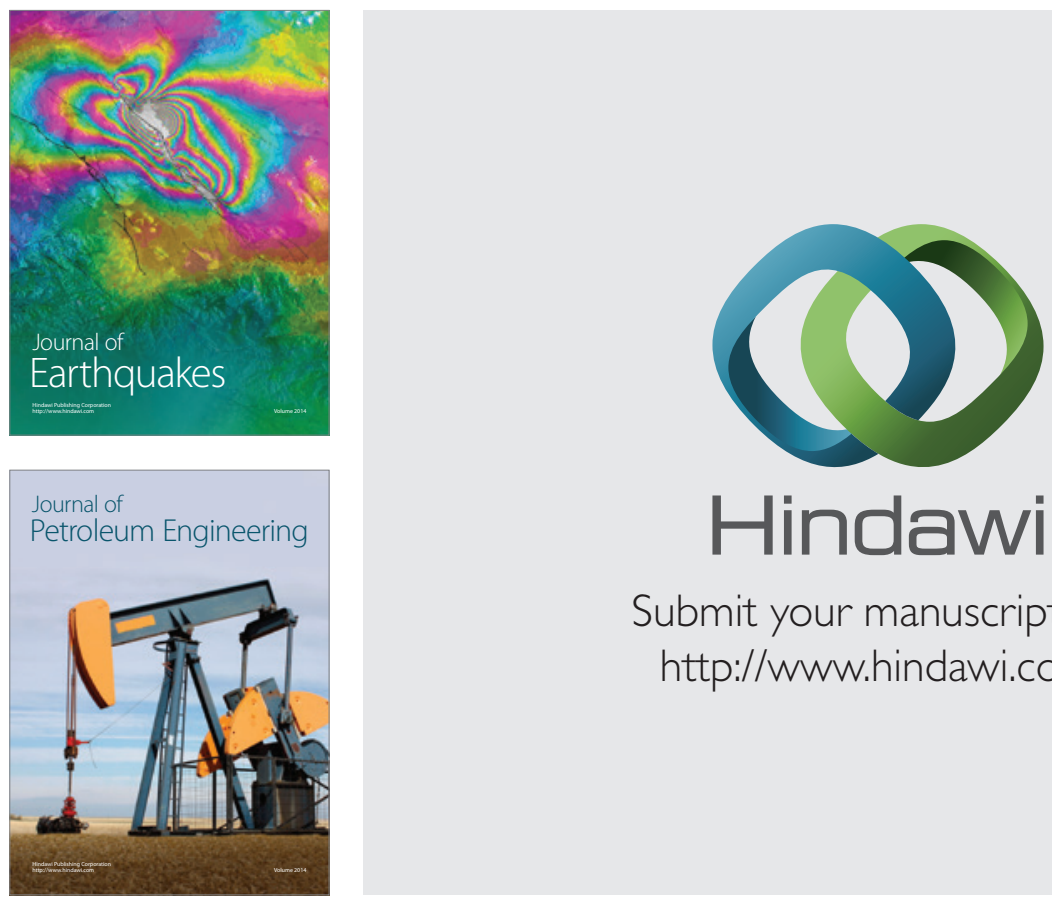

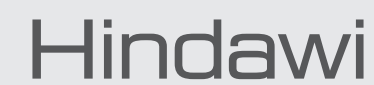

Submit your manuscripts at

http://www.hindawi.com
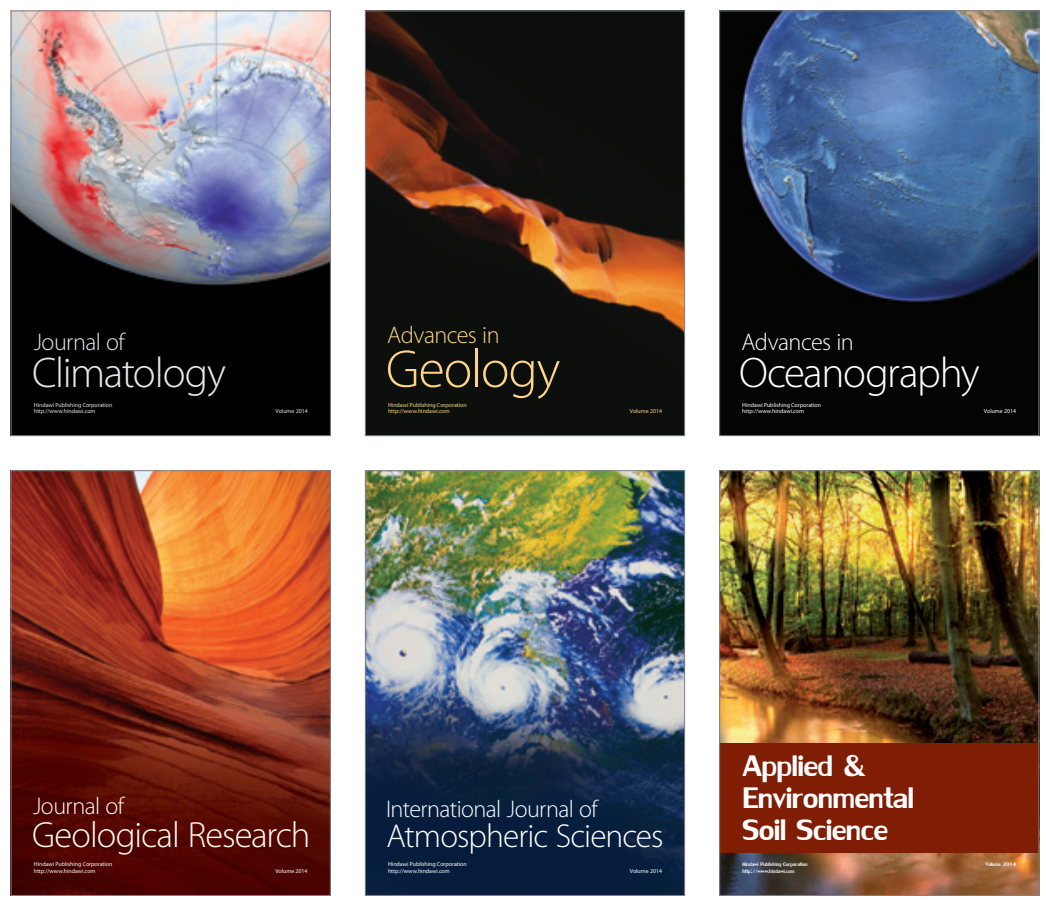
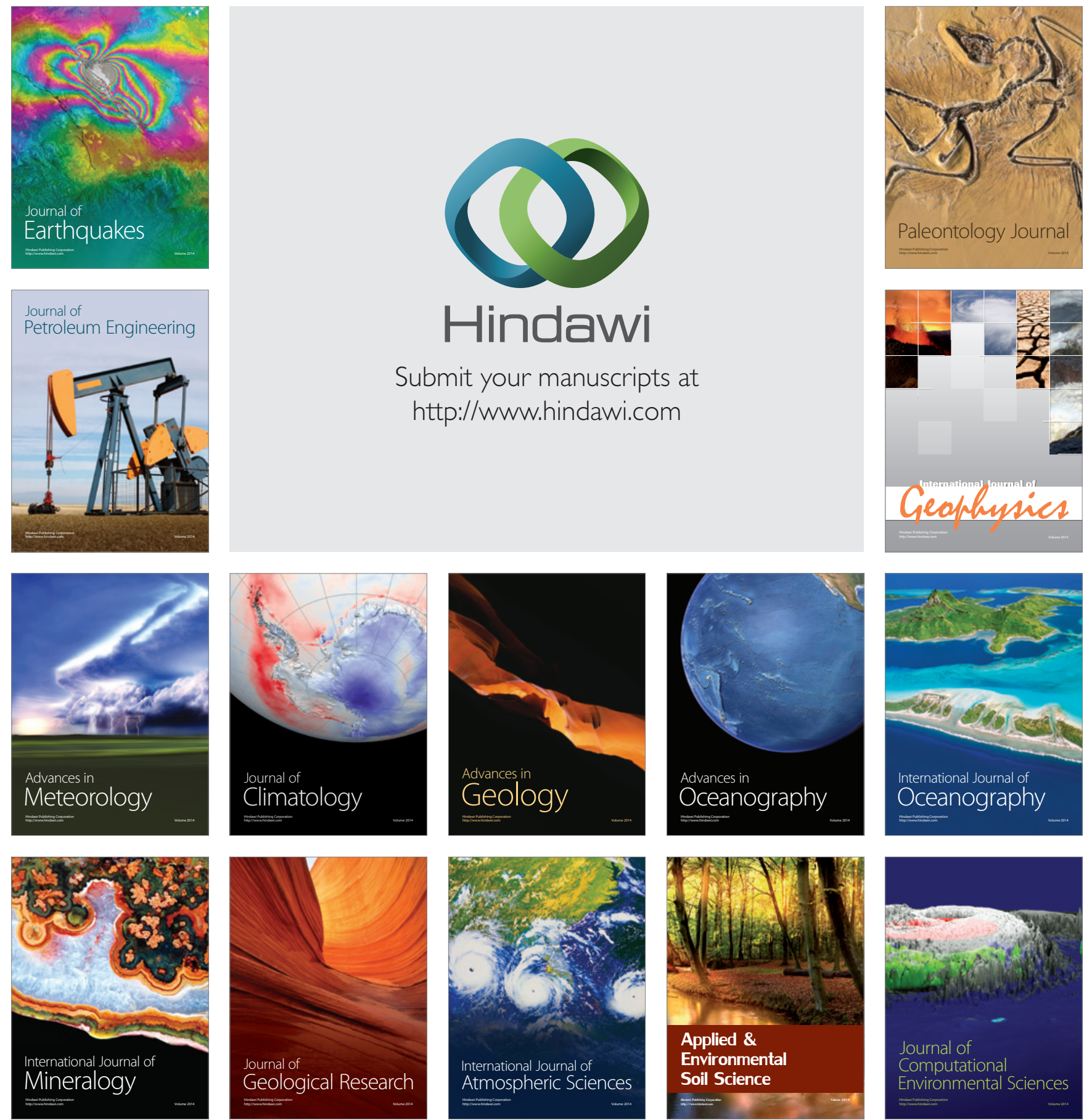